\title{
Pseudo-Elliptic Bandpass Filters Using Closed-Loop Resonator
}

\author{
Norfishah Ab. Wahab ${ }^{\# 1}$, I. Pasya ${ }^{\# 2}$, M. F. Abdul Khalid ${ }^{\# 3}$, I. M. Yassin ${ }^{\# 4}$, S. H. Herman ${ }^{\# 5}$, Z. Awang ${ }^{\# 6}$ \\ ${ }^{\#}$ Microwave Research Institute, Universiti Teknologi MARA, 40450 Shah Alam, Selangor, Malaysia \\ E-mail: ${ }^{2}$ norfishah@ieee.org, ${ }^{2}$ idnin@salam.uitm.edu.my, ${ }^{3}$ mfarid044@salam.uitm.edu.my, ${ }^{4}$ ihsan.yassin@gmail.com, \\ 5hana1617@salam.uitm.edu.my, ${ }^{6}$ zaiki437@salam.uitm.edu.my
}

\begin{abstract}
Based on the closed loop with coupled-line resonator, three $2^{\text {nd }}$ order bandpass filter topologies were built. Each of these topologies offered pseudo-elliptic bandpass response with high selectivity that is suitable for RF and wireless applications. The main advantage of these topologies is that the structures were built from a closed-loop with coupled-line resonator which is easy to control to obtain desired electrical responses. To demonstrate the proposed concepts, the resonators were realized using microstrip technology and all the measurement results showing good agreement with those from the simulations.
\end{abstract}

Keywords — bandpass filter; coupled-line; meander lines, miniaturized; pseudo-elliptic; resonator

\section{INTRODUCTION}

Pseudo-elliptic bandpass filters have been widely implemented in radio channels frequency separation for their high selectivity characteristic [1]-[3]. Features like compact, simple to design, easy to fabricate and low loss bandpass filters are also the main key points to the filter design in meeting the rigorous and modern wireless and RF communication system [4], [5].

Other than that, miniaturization of RF passive components has also been required constantly for the development of low-cost communication system [6]-[8]. Above all things, transmission line should be miniaturized to reduce the size of RF components, since the distributed RF components basically consist of transmission line [9-10]. To mention a few, meander lines have been widely used to achieve compact transmission line. This is due to its small layout area, in which enabled a reduction of chip size [11], [12].

In this paper, three arrangements of bandpass filters were proposed using the closed-loop with coupled-line structure [13]. The first resonator made use of the closed-loop, and new additional coupled-line was introduced at the end of the existing coupled-line. This resonator when simulated gave a reasonable fractional bandwidth of less than 20\%. The second resonator was built based on the same closed loop with coupled-line, but in this arrangement, the coupled-line is a sandwich in between the two closed-loop lines. In terms of fractional bandwidth, the second resonator gives smaller bandwidth compared to the first resonator. The third resonator was proposed to reduce the size of the second topology. In this work, meander lines were proposed to reduce the overall size of the resonator.

All the proposed ideas were tested through simulations using full wave electromagnetic simulation tool, performed on microstrip substrate at the resonance frequency of $2 \mathrm{GHz}$. The entire proposed filters show low insertion loss of less than $3 \mathrm{~dB}$ while the return loss exceeds $10 \mathrm{~dB}$.

\section{MATERIAL AND METHOD}

\section{A. Topology 1: Single Closed-loop with Second Coupled- Line}

In this section, the topology of closed-loop resonator and its electrical response are presented as shown in Fig. 1(a) and 1(b) respectively. This topology exhibits a pseudo-elliptic bandpass filter response with single resonance at the center frequency, $f_{o}$ while two transmission zeros at the lower and upper stopbands with attenuation more than $30 \mathrm{~dB}$ for high selectivity. With three parameters to controlled to obtain desired response, the topology is flexible and can be used as a base cell in developing higher order filters. Various techniques can be applied to achieve this [13]. Indeed, to increase the number of modes of a filter, resonators can be introduced to the existing structure, and this can actually be easily realised. 


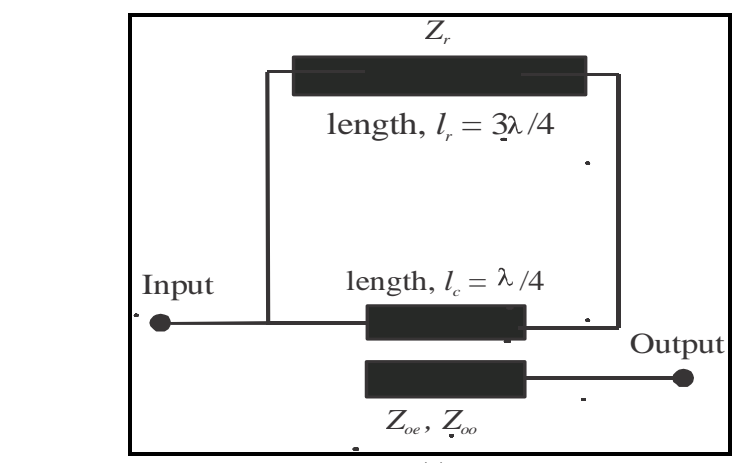

(a)

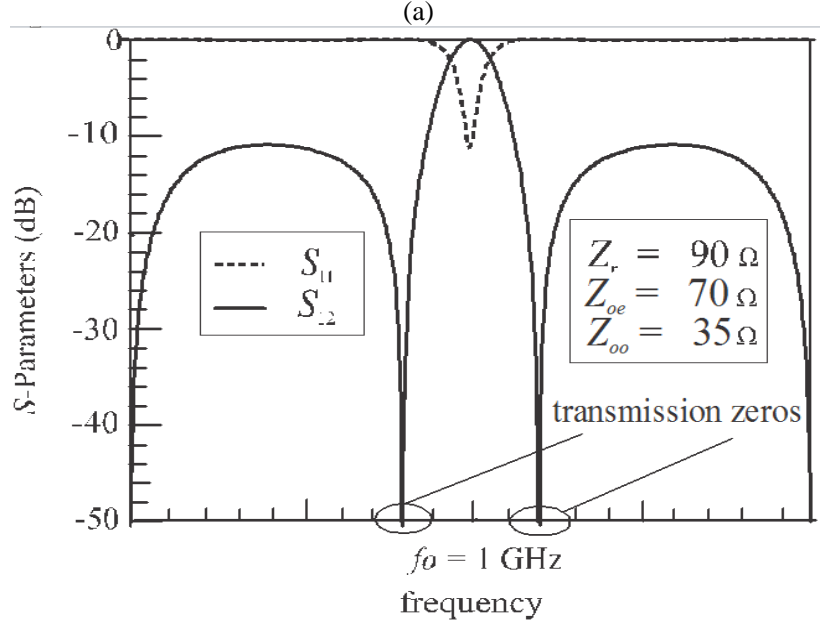

(b)

Fig. 1 A pseudo-elliptic closed-loop resonator: (a) Topology, (b) Ideal response of the resonator [13]

In this work, the closed-loop with a quarter-wavelength coupled-line resonator in Fig. 1(a) was chosen as the base cell to built $2^{\text {nd }}$ order bandpass filters. The characteristics of the newly $2^{\text {nd }}$ order bandpass filters were then investigated in terms of insertion loss, return loss and bandwidth to distinguish the suitability of the implementation of the filters in RF applications. Various techniques were explored such as introducing new coupled line or cascading the basic cells. In the first technique, the basic cell was cascaded with a second quarter-wavelength coupled-line via its output feedline to form a $2^{\text {nd }}$ order bandpass filter.

As illustrated in Fig. 2, the impedances using this configuration can easily be determined by optimizing the circuit using full wave electromagnetic simulator. All the values of the impedances are summarized in Table 1 with new parameters for the second coupled-line, denoted as $Z_{o o l}$ and $Z_{o e l}$ were introduced here. All the impedance values were chosen to be in the accepted range for microstrip technology.

TABLE I

TOPOLOGY 1: IMPEDANCES OF THE CLOSED-LOOP WITH SECOND COUPLEDLINE, DESIGNED AT $2 \mathrm{GHz}$

\begin{tabular}{|l|l|}
\hline Parameter & Value $(\boldsymbol{\Omega})$ \\
\hline Even-mode impedance of the coupled-line, $\mathrm{Z}_{\mathrm{oe}}$ & 70 \\
\hline Odd-mode impedance of the coupled-line, $\mathrm{Z}_{\mathrm{oo}}$ & 40 \\
\hline Impedance of the closed-loop line, $\mathrm{Z}_{\mathrm{r}}$ & 112 \\
\hline $\begin{array}{l}\text { Even-mode impedance of the second coupled- } \\
\text { line, } \mathrm{Z}_{\mathrm{oe} 1}\end{array}$ & 116 \\
\hline $\begin{array}{l}\text { Odd-mode impedance of the second coupled- } \\
\text { line, } \mathrm{Z}_{\mathrm{oo} 1}\end{array}$ & 60 \\
\hline
\end{tabular}

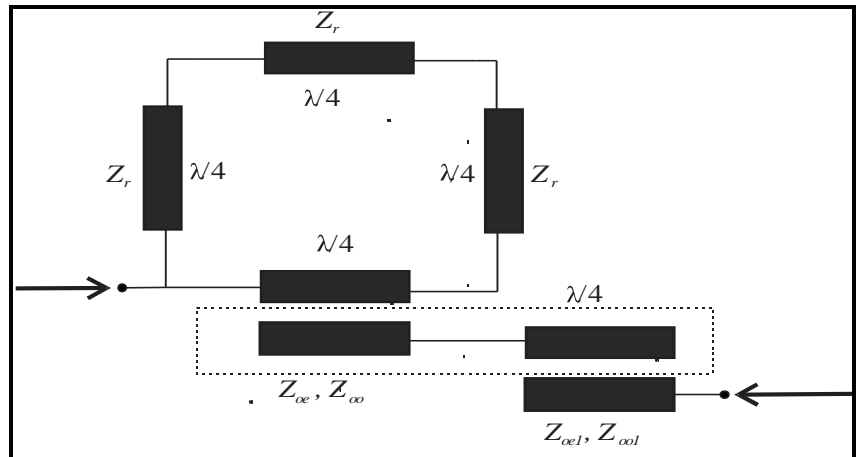

Fig. 2 Ideal circuit of the pseudo-elliptic closed-loop resonator with second coupled-line

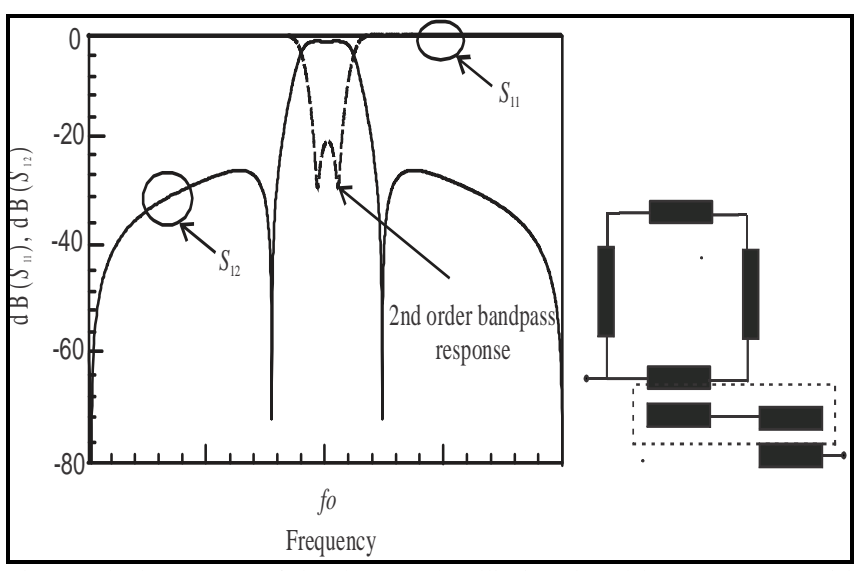

Fig. 3 Ideal response of the the pseudo-elliptic closed-loop resonator with second coupled-line

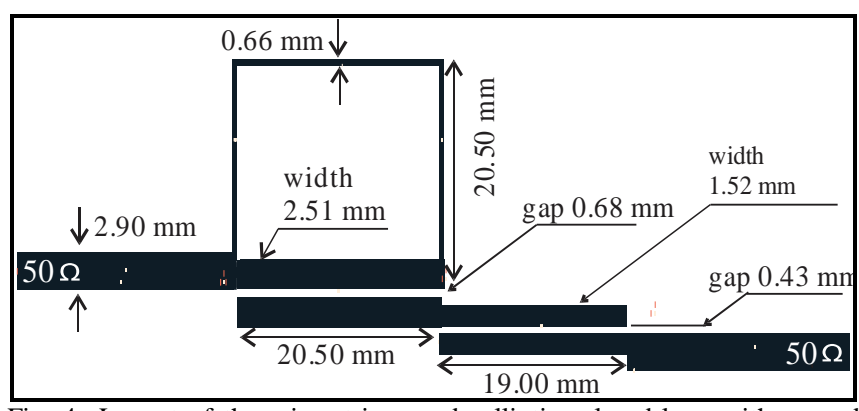

Fig. 4 Layout of the microstrip pseudo-elliptic closed-loop with second coupled-line bandpass filter

The circuit was simulated, and as shown in Fig. 3, the response of the ideal circuit demonstrates a pseudo-elliptic $2^{\text {nd }}$ order bandpass response. It can be seen that two poles were obtained in the passband, resonated at $1.915 \mathrm{GHz}$ and $2.089 \mathrm{GHz}$ giving separation of $0.174 \mathrm{GHz}$. Two transmission zeros frequencies were found; $1.533 \mathrm{GHz}$ for the lower-side stopband and $2.467 \mathrm{GHz}$ for the upper-side stopband, resulted to the fractional bandwidth of $22.75 \%$.

Finally, for implementation purpose, the layout of the resonator was obtained as illustrated in Fig. 4. The dimensions of the first topology of the $2^{\text {nd }}$ order bandpass filter are listed in Table 2. It shows that the lengths of both coupled-lines, L1and L2 are $20500 \mu \mathrm{m}$ and $25100 \mu \mathrm{m}$ respectively; and are considered as a large size of filter. Meanwhile, the dimension of the coupling gap of the first couple-line is $680 \mu \mathrm{m}$ while the second coupled line is 430 $\mu \mathrm{m}$. 
TABLE II

DIMENSIONS OF CHE CLOSED-LOOPS WITH SECOND COUPLED-LINE OF THE $2^{\mathrm{ND}}$ ORDER BANDPASS FILTER

\begin{tabular}{|l|l|}
\hline Parameters & Dimensions $(\boldsymbol{\mu m})$ \\
\hline S1 & 680 \\
\hline L1 & 20500 \\
\hline L2 & 25100 \\
\hline W1 & 660 \\
\hline W2 & 2510 \\
\hline W3 & 1520 \\
\hline L3 & 1900 \\
\hline S2 & 430 \\
\hline
\end{tabular}

B. Topology 2: Two-Closed-Loops Bandpass Filter Topology for Narrow Bandwidth Application
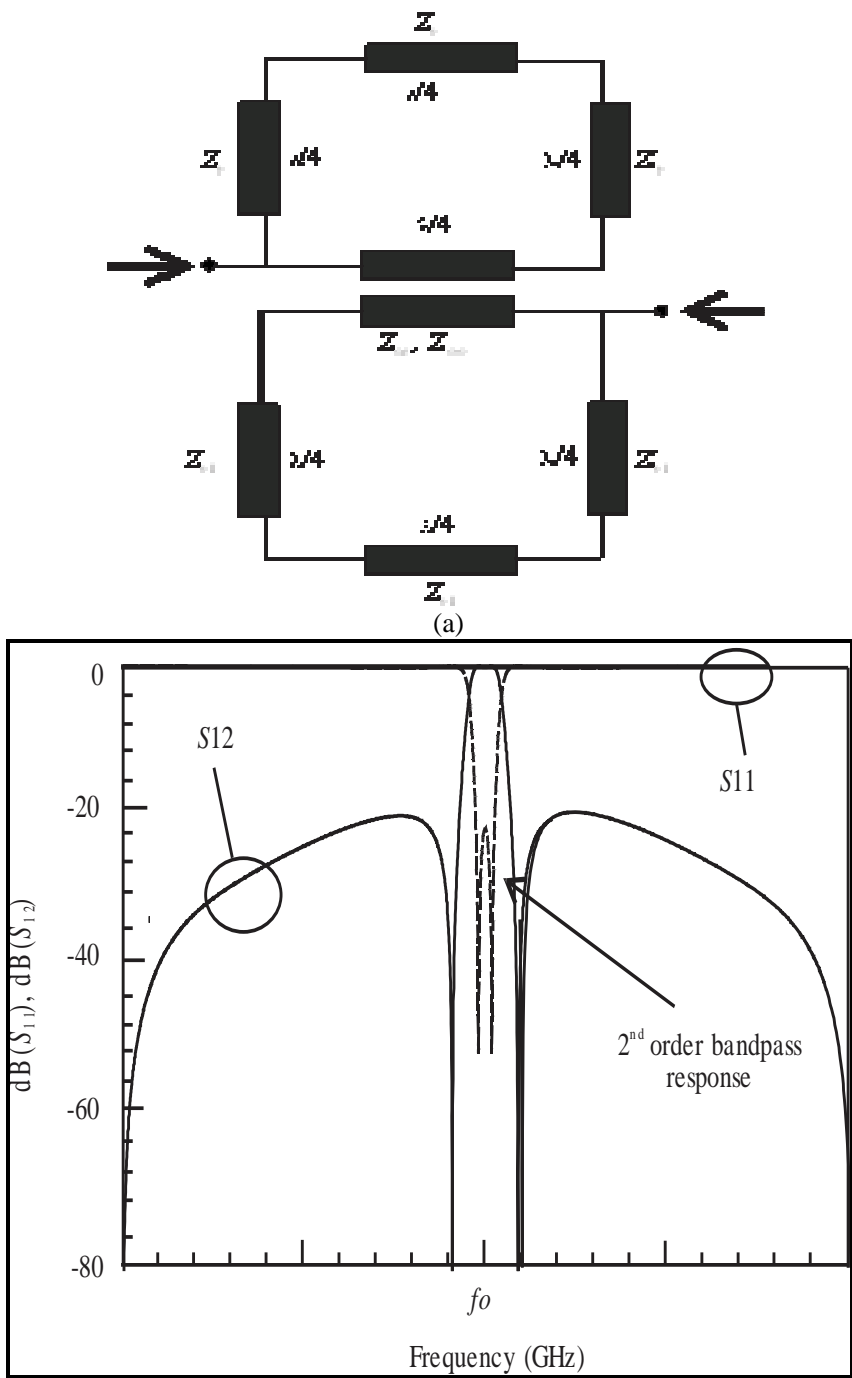

(b)

Fig.5 Ideal circuit of the 2 closed-loops pseudo-elliptic bandpass filter, (a) topology, (b) simulated response

TABLE III

TOPOLOGY 2: IMPEDANCES OF THE TWO-CLOSED-LOOPS OF THE $2^{\mathrm{ND}}$ ORDER BANDPASS FILTER

\begin{tabular}{|l|l|}
\hline Parameter & Value $(\mathbf{\Omega})$ \\
\hline Even-mode impedance of the coupled-line, $\mathrm{Z}_{\mathrm{oe}}$ & 113 \\
\hline Odd-mode impedance of the coupled-line, $\mathrm{Z}_{\mathrm{oo}}$ & 75 \\
\hline Impedance of the first closed-loop, $\mathrm{Z}_{\mathrm{r}}$ & 162 \\
\hline Impedance of the second closed-loop, $\mathrm{Z}_{\mathrm{r} 1}$ & 56 \\
\hline
\end{tabular}

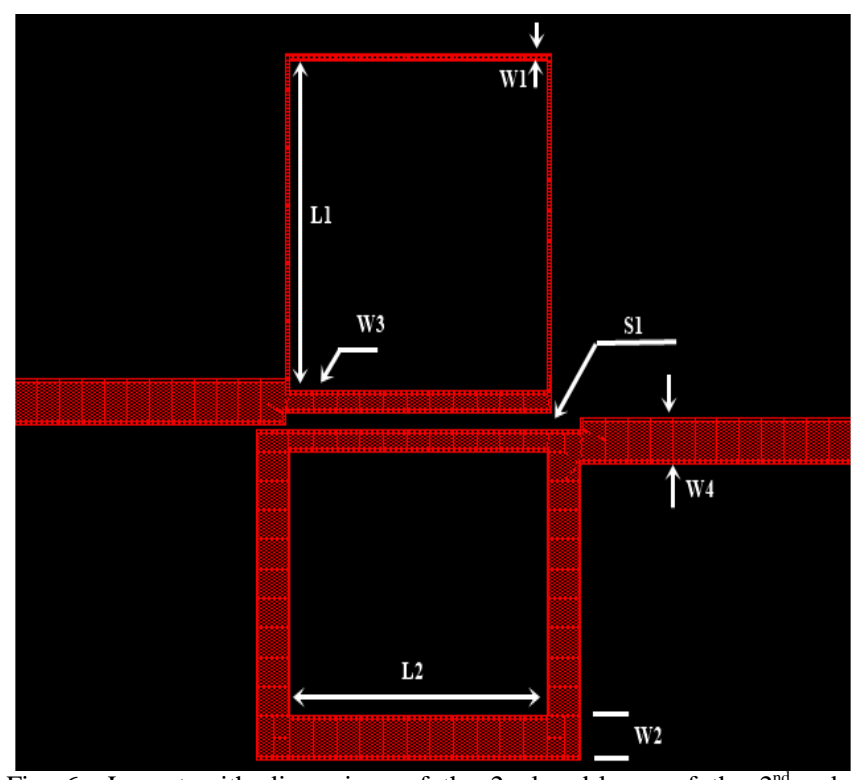

Fig. 6 Layout with dimensions of the 2 closed-loops of the $2^{\text {nd }}$ order bandpass filter

To enrich the filter banks, the basic closed-loop in Fig. 1 was further explored for the creation of second pseudoelliptic $2^{\text {nd }}$ order bandpass filter. In this arrangement, the basic cell is added with a new closed-loop line. It can be seen that the coupled-line is now placed in between the two closed-loops, while the circuit is powered via this coupledline as illustrated in Fig. 5(a). The total circumference of each closed-loops is now equal to one wavelength at the operating frequency $f_{o}$. A quarter-wavelength parallel coupled line is placed at each side of the closed-loop. In this case, the elements of the new closed-loop line are not equal to the base cell's closed-loop line. Therefore, additional parameters of the newly closed-loop line need to be controlled for this higher-order designs as well. As illustrated in Fig. 5, the impedances of this configuration can easily be determined by optimizing the circuit using fullwave electromagnetic simulator. All the values of the impedances are summarized in Table 3 with new parameters for the second closed-loop line, denoted as $Z_{r l}$ is introduced. Again, all the impedance values of this topology were chosen to be in the acceptable range for microstrip technology.

Next, the circuit was simulated, and the filter depicted the pseudo-elliptic frequency response with two poles in the passband region and two transmission zeros at the stopbands as shown in Fig. 5(b). As seen here, two poles in the passband were resonating at $1.960 \mathrm{GHz}$ and $2.039 \mathrm{GHz}$ to exhibit a separation of $79 \mathrm{MHz}$. Two transmission zeros frequencies were found to be very close to the cut-off frequencies, which are $1.818 \mathrm{GHz}$ at the lower-side stopband and $2.182 \mathrm{GHz}$ at the upper-side stopband to give a narrow passband bandwidth of $0.364 \mathrm{GHz}$. The cut-off frequencies of the passband occurred at $1.913 \mathrm{GHz}$ and $2.089 \mathrm{GHz}$ result to the fractional bandwidth of $8.80 \%$ which made the response very sharp, selective and suitable for narrow bandpass response.

Finally, for implementation purpose, the layout of the resonator was obtained as illustrated in Fig. 6. The layout dimensions of the second topology of $2^{\text {nd }}$ order bandpass filter listed in Table 4 shows that the length of both closed- 
loops, $\mathrm{L} 1$ is $22000 \mu \mathrm{m}$ which is considered as a large size of filter. Meanwhile, the dimension of the coupling gap of the filter which is labelling as S1 is $1200 \mu \mathrm{m}$. For a compact size filter, this topology can be further reduced in size by using meander line technique [8], [9].

TABLE IV

Dimensions OF THE TWO-CLOSED-LOOPS OF THE $2^{\text {ND }}$ ORDER BANDPASS FILTER

\begin{tabular}{|l|l|}
\hline Parameters & Dimensions $(\boldsymbol{\mu m})$ \\
\hline S1 & 1200 \\
\hline L1 & 22000 \\
\hline L2 & 1760 \\
\hline W1 & 380 \\
\hline W2 & 2860 \\
\hline W3 & 1400 \\
\hline W4 & 2860 \\
\hline
\end{tabular}

C. Topology 3: Miniaturised $2^{\text {nd }}$ Order Bandpass Filter using Closed-Loop Meander Lines

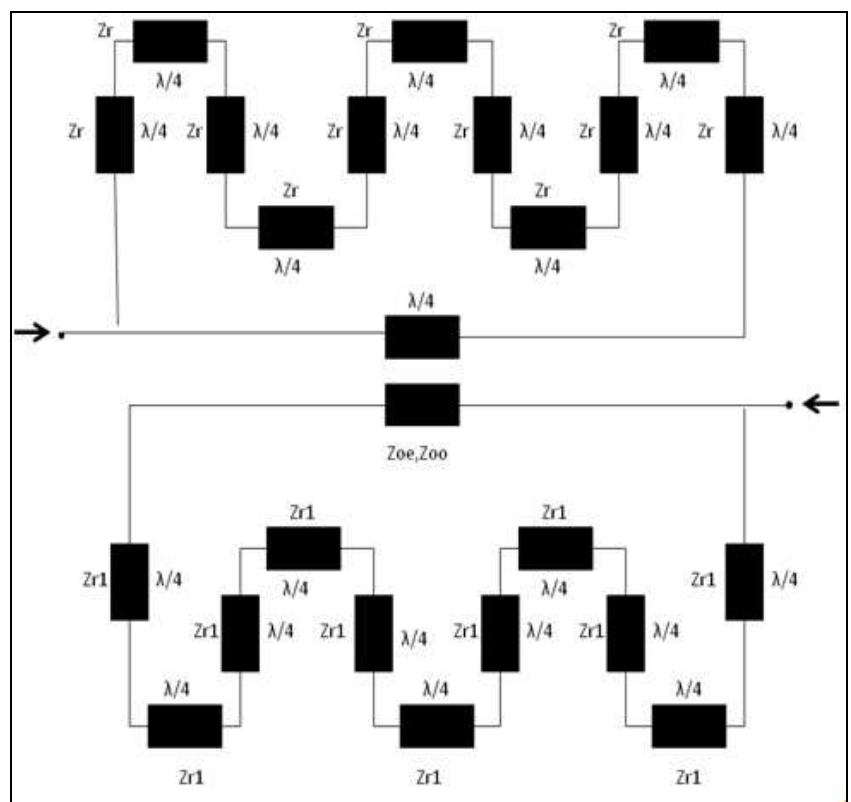

Fig. 7 2nd order bandpass filter for two-closed-loops with meander lines

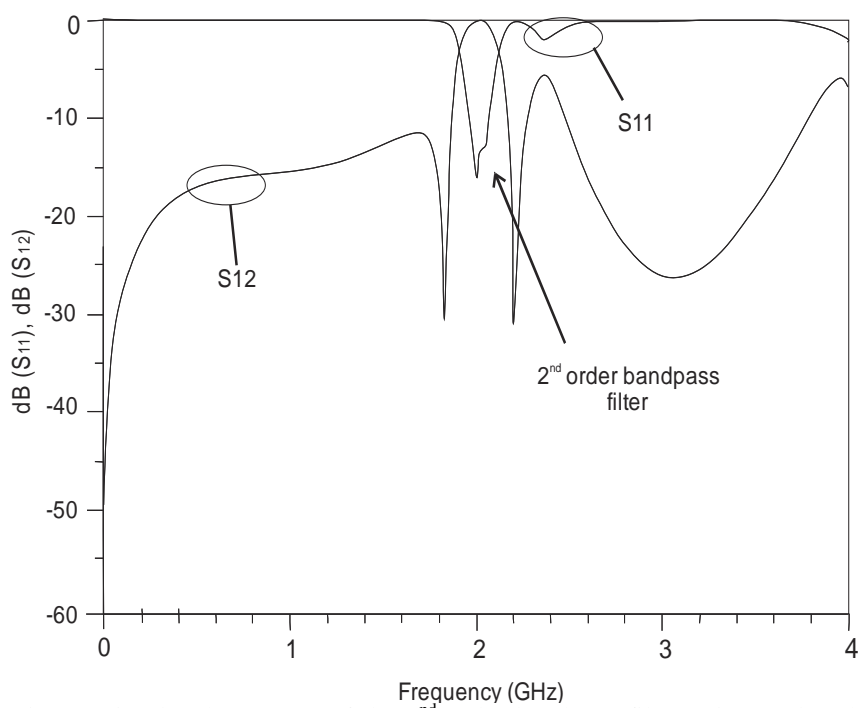

Fig. 8 Simulated response of the $2^{\text {nd }}$ order bandpass filter using 2 closedloops with meander lines

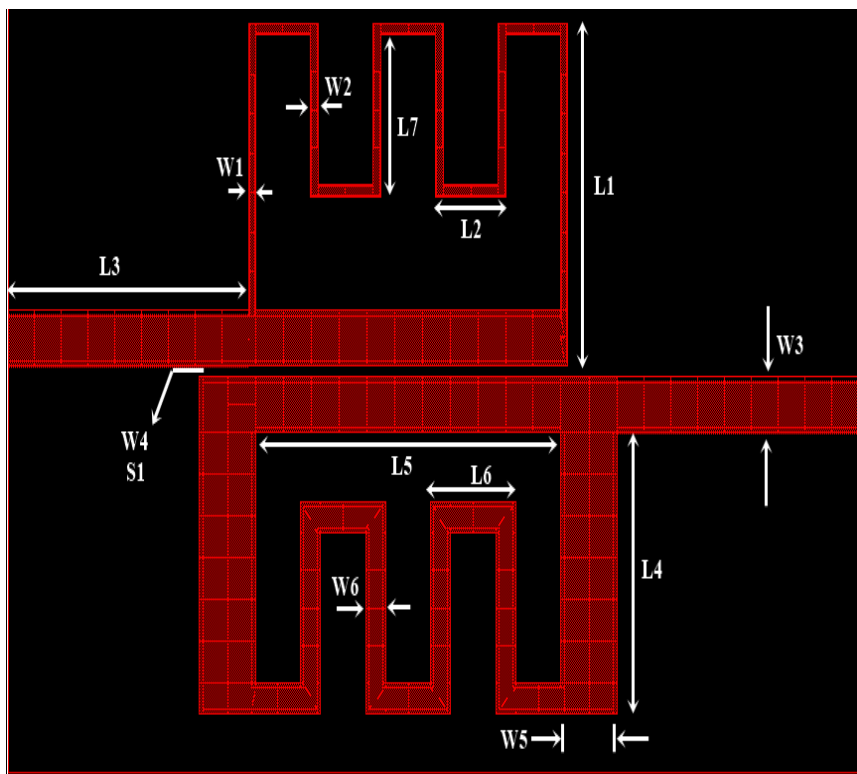

Fig. 9 Layout with dimensions of the 2 closed-loops resonator with meander lines

TABLE V

DIMENSIONS OF THE TWO-CLOSED-LOOPS WITH MEANDER LINES FOR BANDPASS FILTER

\begin{tabular}{|l|c|}
\hline Parameters & Dimensions $(\boldsymbol{\mu m})$ \\
\hline S1 & 300 \\
\hline L1, L4 & 11000 \\
\hline L2 & 3425 \\
\hline L3 & 15000 \\
\hline L5 & 19000 \\
\hline L6 & 2800 \\
\hline L7 & 6000 \\
\hline W1 & 380 \\
\hline W2 & 470 \\
\hline W3, W4 & 2200 \\
\hline W5 & 3460 \\
\hline W6 & 1250 \\
\hline
\end{tabular}

Based on the parameters values in Table 5, the length of the top closed-loop, L1 is $11000 \mu \mathrm{m}$ with the gap coupling of $300 \mu \mathrm{m}$. The gap is very much reduced now compared to the actual length of the second topology. The length of each meander lines of the top closed-loop is $3425 \mu \mathrm{m}$ while the length of each meander lines of the bottom closed-loop is $2800 \mu \mathrm{m}$.

In this proposed resonator, meander lines were introduced to reduce the size of the second resonator in Fig. 6. Taking into account, the responses must be a pseudo-elliptic $2^{\text {nd }}$ order bandpass filter with high selectivity; the lines must be carefully optimized so that the response can be maintained. Fig. 7 illustrates the third design of the $2^{\text {nd }}$ order bandpass filter with both sides of the closed-loops are shaped in meander, and resonate at $2 \mathrm{GHz}$ center frequency for narrowband application. The topology is optimized using electromagnetic simulator to obtain desired response of pseudo-elliptic response.

This bandpass filter was then simulated using electromagnetic simulator and the simulation response was recorded. Fig. 8 illustrates the simulated response of the third pseudo-elliptic $2^{\text {nd }}$ order bandpass filter topology. It can be seen that the resonance frequencies were at $1.981 \mathrm{GHz}$ and $2.142 \mathrm{GHz}$. The $2^{\text {nd }}$ order response is centred at $2 \mathrm{GHz}$ with 
transmission zeros obtained at lower transmission zeros of $1.857 \mathrm{GHz}$ and higher transmission zeros of $2.154 \mathrm{GHz}$. The insertion loss is obtained at $0.471 \mathrm{~dB}$. The fractional bandwidth of this topology is $9.54 \%$. The layout with simulated dimensions of the third $2^{\text {nd }}$ order bandpass filter with meander lines is shown in Fig. 9.

\section{RESULTS AND DISCUSSION}

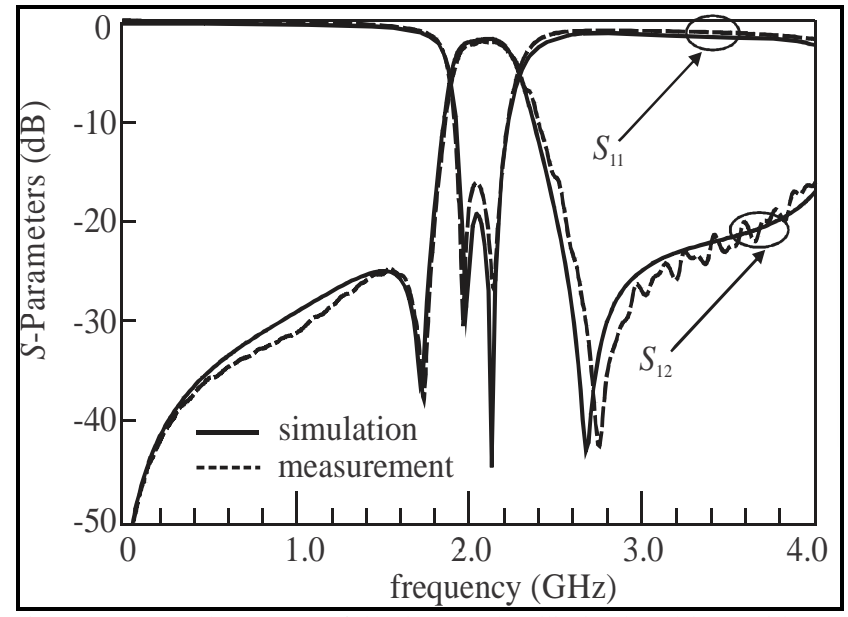

Fig. 10 Measured response of the the pseudo-elliptic closed-loop with new coupled-line bandpass filter

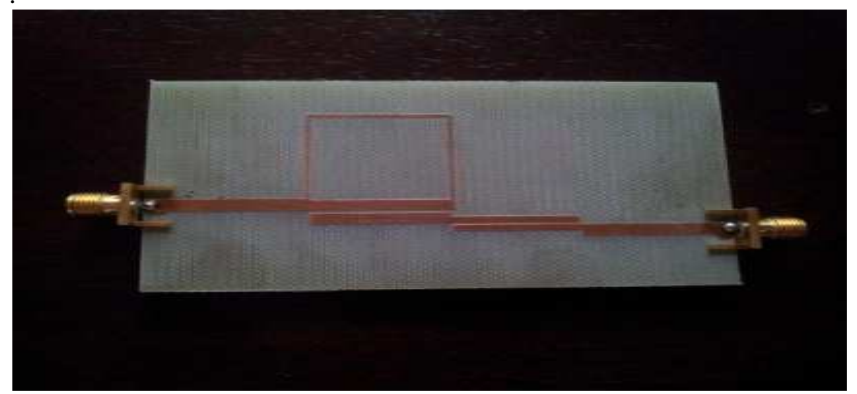

Fig. 11 Fabricated photo of the the first topology base on the base cell with second coupled-line

For proof of concept, all the proposed resonators are implemented using microstrip technology and were designed at $2 \mathrm{GHz}$. These filters are specially built to be used in RF or any microwave applications systems.

The first topology made used of second coupled-line, coupled to the base cell was fabricated. The resonator was implemented using microstrip technology on FR4 substrate, with a chosen center frequency of $2 \mathrm{GHz}$. The characteristics of the substrate are given by: $\varepsilon_{r}=5, h=1.6 \mathrm{~mm}$ and $\tan \delta=$ 0.02 . The results of electromagnetic simulation and measurement are shown in Fig. 10. It can be seen that the measured resonant frequency in is slightly shifted from the simulated one, $2.14 \mathrm{GHz}$ while two transmission zeros are found at $1.71 \mathrm{GHz}$ and $2.57 \mathrm{GHz}$. The insertion loss is at 2 $\mathrm{dB}$ while the attenuation at $1.5 f_{o}$ is $10 \mathrm{~dB}$. Fig. 11 illustrates the fabricated resonator for the first topology to prove the concept.

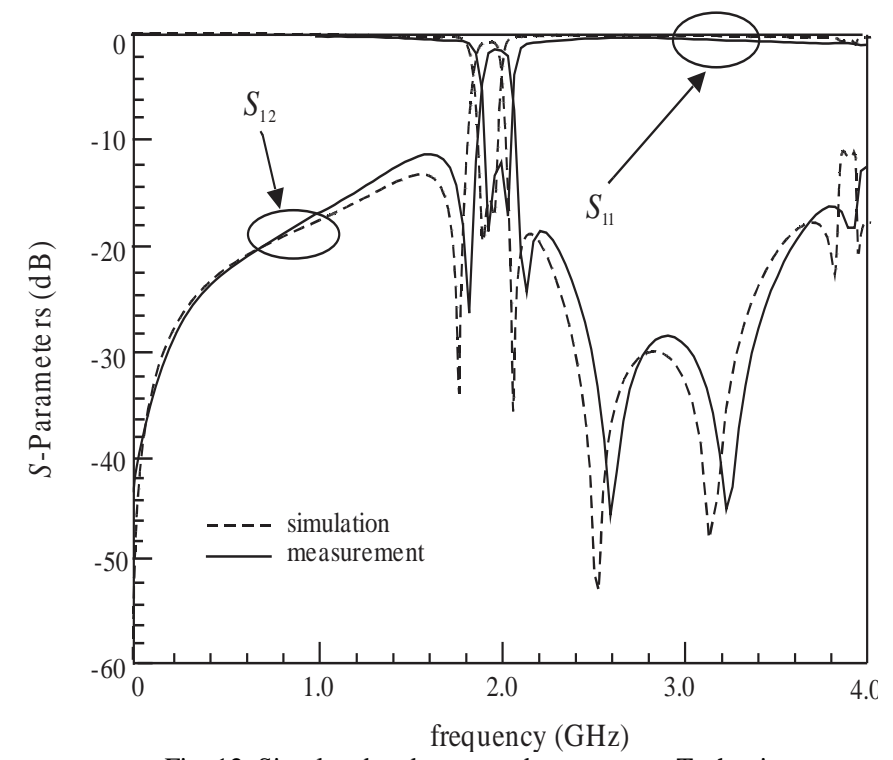

Fig. 12 Simulated and measured response on Tachonic

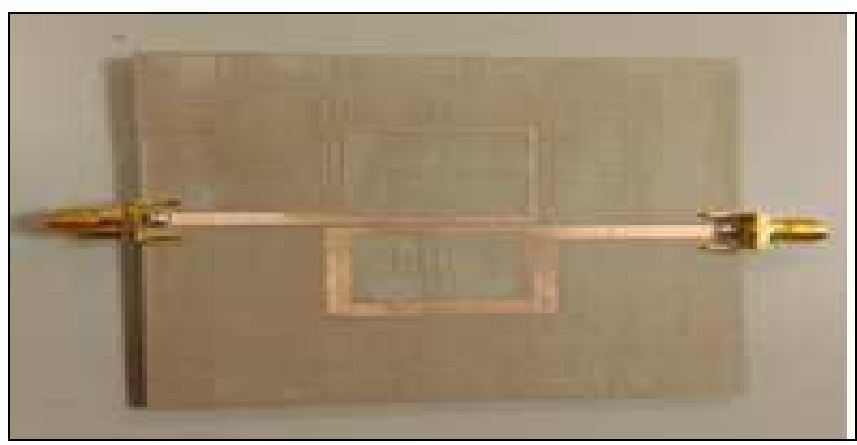

Fig. 13 Fabricated photo of the second topology: two closed-loops resonator

The second topology was implemented on Taconic substrate with a thickness of $1.64 \mathrm{~mm}$, relative dielectric constant $(\varepsilon r)$ of 4.5 and loss tangent of 0.0035 which is lower than FR-4 was used in implementing the second topology. The performance of the filter was measured and compared with simulated response, and the results are presented in Fig. 12. The measured results show that the two resonance frequencies are found at $1.945 \mathrm{GHz}$ and $2.050 \mathrm{GHz}$ while center frequency is positioned at $1.998 \mathrm{GHz}$ giving a fractional bandwidth of $8.76 \%$.

Meanwhile, a transmission zeros was found at the lower stop-band occur at $1.840 \mathrm{GHz}$ and two transmission zeros at the upper stopband occurred at $2.155 \mathrm{GHz}$ and $2.610 \mathrm{GHz}$ giving a passband bandwidth of $315 \mathrm{MHz}$. As such, the rejection level at the stopbands exceeded $24 \mathrm{~dB}$ while insertion loss and return loss are found at with $1.55 \mathrm{~dB}$ and $13.65 \mathrm{~dB}$ respectively. For proof of concept, the fabricated resonator is shown in Fig. 13.

The third topology was implemented on Taconic. The measured responses of the second and third resonators are compared as shown in Fig. 14. It was found that the fractional bandwidth of the third resonator had increased by $1.5 \%$ compared to the second resonator. The rejection level for both filters exceeding $30 \mathrm{~dB}$ which is good performance. 


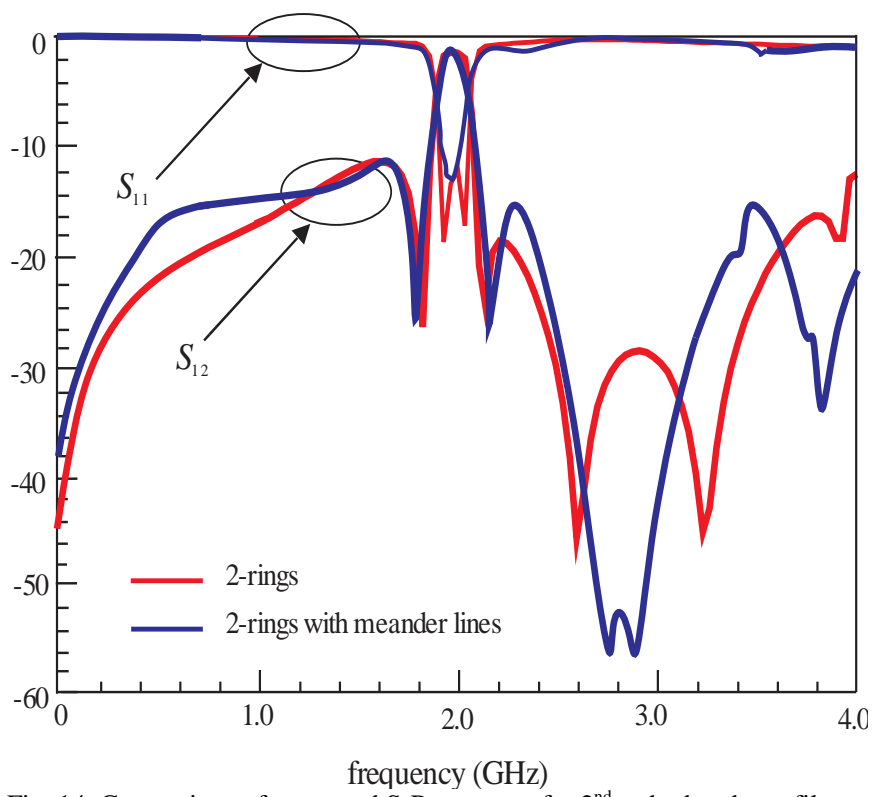

Fig. 14 Comparison of measured S-Parameters for $2^{\text {nd }}$ order bandpass filters

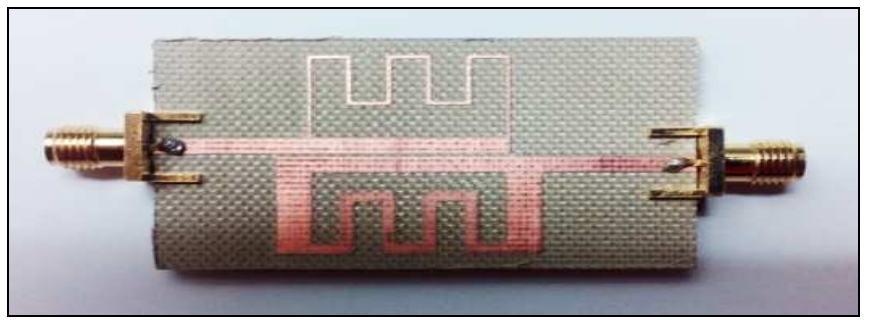

Fig. 15 Fabricated photo of the third topology: Two closed-loops with meander lines resonators on Taconic microstrip substrate

The insertion loss of the third resonator has improved about $1.47 \%$ while the return loss exceeded $10 \mathrm{~dB}$ compared to the second resonator. The fabricated filter size of the third topology was successfully reduced by $56.5 \%$ from the second topology. The fabricated photo of the third topology is shown in Fig. 15 as proof of concept. The size of the proposed filter is $5.3 \mathrm{~cm} \times 3.25 \mathrm{~cm}$. The length of the filter was successfully reduced more than half compared to the second topology.

Finally, all the responses for the three resonators are tabulated in Table 6. It can be seen that all the resonators had shown their own specific characteristics that are suitable for RF applications.

TABLE VI

COMPARISONS OF All THE RESONATORS' MEASURED RESPONSES

\begin{tabular}{|c|c|c|c|}
\hline Topology & $\begin{array}{l}\text { Topology } 1 \\
\text { Closed-Loop with Second Coupled-Line }\end{array}$ & $\begin{array}{l}\text { Topology } 2 \\
\text { Closed-Loop with Coupled-Line }\end{array}$ & $\begin{array}{l}\text { Topology } 3 \\
\text { Closed-Loop Meander Lines }\end{array}$ \\
\hline $\begin{array}{l}\text { Microstrip } \\
\text { substrate }\end{array}$ & $\begin{array}{l}\text { FR-4 } \\
\varepsilon_{r}=4.1 \\
h=1.6 \mathrm{~mm} \\
\tan \delta: 2 \times 10^{-2}\end{array}$ & $\begin{array}{l}\text { Tachonic } \\
\varepsilon_{r}=4.5 \\
h=1.6 \mathrm{~mm} \\
\tan \delta: 3.5 \times 10^{-3}\end{array}$ & \\
\hline Insertion loss, $\mathrm{dB}$ & 2.23 & 1.55 & 1.245 \\
\hline Fractional, BW (\%) & 18.93 & 8.76 & 10.23 \\
\hline Size & $\begin{array}{l}x=79.51 \\
y=46.84\end{array}$ & $\begin{array}{l}x=71.66 \\
y=46.84\end{array}$ & $\begin{array}{l}x=52.84 \\
y=27.63\end{array}$ \\
\hline
\end{tabular}

\section{CONCLUSION}

In this paper, three pseudo-elliptic $2^{\text {nd }}$ order bandpass resonator topologies were proposed based on the closed-loop resonator. All the topologies showed the advantages of high selectivity and prominent filter responses. The investigation of the resonators showed that the impedances of each resonator were optimized to obtain desired response by controlling the impedances of the closed-loops and the coupled-lines. Meanwhile, all the bandwidths of the resonators can be controlled by varying the gap in each resonator. Meander lines were introduced in the third topology to reduce the size and at the same time improved the response compared to the second topology. It has been proven in this work that meander structure [14], [15] enables the filter to be flexibly miniaturized, and this approach can be easily applied in various type coupled filters too. Finally, all the resonators were fabricated on microstrip substrates. The measured results had shown good agreement with the simulations while the filters demonstrated high selectivity, sharp rejection skirts and stopband attenuation levels above $24 \mathrm{~dB}$.

In view of the experimental results, this arrangement scheme realized a filter not only with high selectivity and sharp skirt but also compact size, good performance and simple design at low cost. Therefore, these proposed topologies are suitable for advanced microwave communication applications that require spectral efficiency applications.

\section{ACKNOWLEDGMENT}

We would like to thank Ministry of Education Malaysia and Research Management Institute(RMI), Universiti Teknologi MARA with grant number 600-RMI/DANA 5/3/LESTARI (72/2015) for funding this project.

\section{REFERENCES}

[1] C. Z. Hua and W. Chao, "Design of stepped impedance resonator bandpass hairpin filter," in Proc. ICEPT' 16, 2016, p. 1409.

[2] S. W. Ren, H. L. Peng, J. F. Mao, and A. M. Gao, "Compact quasielliptic wideband bandpass filter using cross-coupled multiple-mode resonator," IEEE Microwave and Wireless Components Letters, vol. 22, pp. 397-399, Aug. 2012.

[3] S. V. Kumar and A. R. Harish, "Dual mode bandpass filter using trefoil torus knot resonator," in Proc. IEEE IMaRC'15, 2015, p. 419.

[4] S. B. Cohn, "Parallel-couple transmission line resonator filter," IRE Transactions on Microwave Theory and Techniques, vol. 6, pp. 223231, Apr. 1958.

[5] Z. Awang, Microwave Systems Design, Berlin, Germany: Springer, 2014. 
[6] D. A. Letavin and V. A. Chechetkin," Miniature microwave bandpass filter with two circular spiral resonators," in Proc. ICACCI'16, 2016, p. 2315.

[7] R. Garg, I. Bahl, and M. Bozzi, Microstrip Lines and Slotlines, 3rd ed., London, UK: Artech House, 2013.

[8] A. Munir, "Development of dual-band microstrip bandpass filter based on split ring resonator," in Proc. ICEAA'16, 2016, p. 712.

[9] T. W. Kim, Y. J. Shin, and Y. S. Kim, "S-parameter characteristics of microstrip meander line," in Proc. IEEK'08, 2008, p. 1201.

[10] A. Khaleghi, "Dual band meander line antenna for wireless LAN communication," IEEE Transactions on Antennas and Propagation, vol. 55, pp. 1004-1009, Mar. 2007.

[11] T. Y. Xiang, T. Lei, and M. Peng, "Miniature dual mode bandpass filter based on meander loop resonator with source load coupling," in Proc. APMC'15, 2015, p. 1.

[12] K. G. Avanash and I. S. Rao," Design of compact meandered dual mode wideband microstrip bandpass filter using tuning stubs," in Proc. ICMAP'15, 2015, p. 1.
[13] N. A. Wahab, M. K. M. Salleh, Z. I. Khan, and E. A. Rashid, "Reconfigurable ring filter with controllable frequency response," The Scientific World Journal, vol. 2014, pp. 1-11, Jul. 2014.

[14] I. M. Yassin, A. Zabidi, M. S. A. M. Ali, N. M. Tahir, H. A. Hassan, H. Z. Abidin, and Z. I. Rizman, "Binary particle swarm optimization structure selection of nonlinear autoregressive moving average with exogenous inputs (NARMAX) model of a flexible robot arm," International Journal on Advanced Science, Engineering and Information Technology, vol. 6, pp. 630-637, Oct. 2016.

[15] M. N. M. Nor, R. Jailani, N. M. Tahir, I. M. Yassin, Z. I. Rizman, and R. Hidayat, "EMG signals analysis of BF and RF muscles in autism spectrum disorder (ASD) during walking," International Journal on Advanced Science, Engineering and Information Technology, vol. 6, pp. 793-798, Oct. 2016. 